\title{
Imagens representacionais das políticas públicas à educação e à saúde, no imaginário de um grupo de idosos da comunidade Quilombola-Kalunga, de Monte Alegre de Goiás
}

Fátima Gonçalves Messias Takahashi a

Vicente Paulo Alves ${ }^{b}$

\section{Resumo}

As Teorias do Imaginário de Gilberto Durand e o Teste AT-9 de Yves Durand permitem levantar imagens individuais e grupais. A pesquisa foi realizada por meio de entrevistas não estruturadas sobre o imaginário de um grupo de idosos da comunidade Quilombola-Kalunga, em Monte Alegre de Goiás (Brasil). As entrevistas versaram também sobre as políticas públicas de educação e de saúde, que podem dar melhores condições de vida a esses idosos. Sabe-se que a oferta e o controle das diretrizes das políticas públicas em educação e em saúde estão transcritas na Constituição Brasileira de 1988 e no Estatuto do Idoso (Lei $n^{\circ} 10.741 / 2003$ ), mas, efetivamente, elas não chegam aos lugares mais remotos do País. $\mathrm{O}$ relato da pesquisa busca demonstrar que, junto com a cultura do silêncio dos kalungas, está a omissão e o clientelismo do poder público, que deixa essa população sem atendimento na área de educação e de saúde.

Palavras-chave: Imaginário. Idoso da comunidade Quilombola-Kalunga. Políticas públicas em educação e em saúde.

\footnotetext{
a Secretaria Estadual da Saúde. Monte Alegre de Goiás, Goiás, Brasil. Secretaria Estadual da Educação (Núcleo Tecnológico da Educação - NTE).

b Universidade Católica de Brasília - UCB, Programa de Pós-Graduação Stricto Sensu em Gerontologia. Distrito Federal, Brasília, Brasil.
} 


\section{Introdução}

As particularidades dos idosos afrodescendentes da comunidade tradicional Quilombola-Kalunga mostram que ela conseguiu permanecer preservada em sua cultura e tradição, ao mesmo tempo em que despertam o interesse de vários pesquisadores sobre o tema das políticas públicas interculturais de educação e de saúde, que possam também atender às exigências do multiculturalismo. Nesta pesquisa, optou-se por utilizar a Antropologia do Imaginário de Gilberto Durand (1988) e o Arquétipo Teste de Nove Elementos (AT-9), criado por Yves Durand (1988), por julgar serem uma teoria e um método capazes de perscrutar a realidade e o imaginário dessa comunidade.

O psicólogo francês Yves Durand (1910-2003) criou o AT-9, a partir da Teoria do Imaginário de Gilbert Durand (1921-2012), sociólogo e antropólogo francês. O AT-9 é um instrumento usado para detectar o imaginário subjacente de um grupo de pessoas nos seus pensamentos palavras e ações. O AT-9 é composto por um desenho, uma narrativa da história que a pessoa faz do desenho, respostas a um questionário e um quadro-síntese com as atribuições de imagens, função e simbolismo que foram dados a cada um dos nove elementos, estímulos arquetípicos do teste. Os nove elementos do teste são: 1) queda; 2) espada; 3 ) refúgio; 4) monstro devorante; 5) algo cíclico (que gira, produz ou progride); 6) personagem; 7) água; 8) animal; e 9) fogo. O teste permite detectar o "trajeto antropológico", conceituado por Gilbert Durand (1989, p.12), como “[...] caminho que se realiza na circularidade recursiva entre as pulsões internas, psiquismo e as pressões externas do meio cósmico e social dos indivíduos e ou dos grupos".

Assim, o AT-9 foi aplicado em um grupo de idosos da comunidade Quilombola-Kalunga, de Monte Alegre de Goiás (Brasil), na tentativa de identificar as representações da realidade vivida, redescobrindo seus sonhos e ideiais de educação e de saúde, na busca da correspondência com suas vidas e seus pensamentos, suas complexidades biopsicossociais, histórica e cultural, bem como compreender e relacionar com a estrutura do imaginário desse universo mítico vivido por eles.

Apontar políticas públicas em educação e em saúde dentro de uma diversidade de comosvisões é, de certa maneira, promover a dignidade dessa população esquecida pelo Estado e que, muitas vezes, esquece também a sua realidade multicultural e não atende às diferentes necessidades da comunidade. Acredita-se que essa realidade precisa ter correspondência com os direitos firmados e instituídos na legislação brasileira [particularmente, a Constituição Brasileira de 1988 (BRASIL, 2001) e o Estatuto do Idoso, Lei ${ }^{\circ} 10.741 / 2003$ (BRASIL, 2003)], expressos na 
fala dos sujeitos da pesquisa, os idosos quilombolas-kalungas de Monte Alegre de Goiás, conforme se verá adiante.

Nos depoimentos e nos protocolos AT-9, foi possível descobrir a estrutura do imaginário que subjaz a eles: a forma como se entendem e agem, a luta por seus direitos, o que corresponderia a um imaginário heróico/esquizomorfo. Constata-se isso, sobretudo, quando se acomodam e deixam as coisas acontecerem, sem reações contra as situações que lhes desagradam, tendo uma identificação de um imaginário com estrutura mística/antifrásica; ou ainda, intercalam-se em momentos distintos e, ao mesmo tempo, tendo reações de heroísmo e tranquilidade, o que demonstraria um imaginário sintético/disseminatório, conforme classifica Gilbert Durand (1989).

Com a realização do teste com o grupo, as imagens representacionais foram levantadas, complementando a ação de conhecer o imaginário, por meio das entrevistas, ouvindo a fala dos sujeitos. Os idosos quilombolas desenharam as imagens dos nove elementos, por meio do estímulo dado pelos pesquisadores, de forma que pudessem imaginar uma história que entrelaçasse esses elementos. Mesmo que alguns deles fossem analfabetos, eles conseguiram contar a história imaginada de forma oral. Conseguiram também responder ao elenco de questões pertinentes ao teste e prencheram o quadro síntese, identificando cada um dos nove elementos com as imagens pictóricas oferecidas no protocolo do teste, com a função atribuída a cada um desses elementos da história imaginada, indicando o simbolismo encontrado para cada elemento, como preconiza o teste.

O objetivo do AT-9 é detectar o imaginário subjacente aos pensamentos, palavras e ações de cada sujeito e do grupo. O imaginário é encontrado no trajeto antropológico, permitindo uma circularidade entre interior e exterior na voz dos sujeitos. Assim, buscou-se conhecer a realidade externa desse grupo, particularmente, quando os idosos relembraram sua vida no quilombo e em registros documentais de suas origens históricas, situação social atual e pregressa, seus mitos, rituais e vitórias no tempo e no espaço.

Dentro do contexto em que o grupo vive, é possível inferir, por meio da escuta sensível dessa comunidade, o imaginário do grupo, pois ele é resultado do amálgama do exterior patente com um interior latente que forma o trajeto antropológico. As imagens representacionais foram buscadas diretamente na voz dos próprios idosos da comunidade Quilombola-Kalunga e nos registros dos protocolos do teste referido, uma vez que a realidade foi observada e contada pelos idosos afrodescedentes. 


\section{Metodologia}

A pesquisa realizada, de natureza qualitativa, bibliográfica, aplicou o instrumento denominado AT-9 de Yves Durand (1988) com os idosos da Comunidade Quilombola-Kalunga, cuja escolha foi aleatória, isto é, por conveniência, segundo a disponibilidade e o interesse dos sujeitos em participar da pesquisa. Para o estudo do imaginário subjacente dos idosos, procurou-se dar significado às palavras, aos pensamentos e às ações deles, por meio das estruturas antropológicas do imaginário de Gilbert Durand (1989).

Para Yves Durand, o trajeto antropológico dos entrevistados é encontrado a partir do estudo do imaginário dos idosos, de suas histórias de vida e nas imagens representadas por desenhos previamente sugeridos pelos pesquisadores, ou seja, segue-se um protocolo que foi preconizado pelo autor, denominado de Arquétipo Teste de Nove Elementos (AT-9). O AT-9 é um teste para conhecer o imaginário dos grupos, com base nos pressupostos da Teoria do Imaginário de Gilbert Durand (1989). Esses nove elementos são estímulos arquetípicos que o pesquisador sugere que o sujeito faça para construir uma história/discurso/narrativa, por meio de um desenho que represente uma história pictórica imaginada, ao mesmo tempo em que responde a um questionário e preenche um quadro com "representações, funções e simbolismos" atribuídos pelo entrevistado à dramatização/história para cada um dos nove elementos do teste: 1) queda; 2) espada; 3) refúgio; 4) algo de cíclico (que roda, que gira, transforma-se etc.); 5) monstro; 6) personagem; 7) água; 8) animal; e 9) fogo.

Para compreender os dados, foram feitos três tipos de análises: a elemencial, a funcional e a estrutural, conforme Yves Durand, que poderão ser enriquecidos/ completados com as imagens representacionais advindas das falas, dos gestos e dos depoimentos oferecidos/colhidos com os sujeitos da pesquisa. O AT-9 é um instrumento que busca a consecução dos dados míticos simbólicos, auxiliado pelas falas dos sujeitos.

O desenho feito pelos entrevistados é chamado de genograma, "[...] um mapa que oferece uma imagem gráfica da estrutura familiar ao longo de várias gerações, que esquematiza as grandes etapas do ciclo de vida familiar, além dos movimentos emocionais a ele associados" (MIERMONT et al., 1994, p.291).

\section{Os quilombos no Brasil}

Os quilombos nos remetem aos vários tempos e espaços históricos; em primeiro lugar, à África do século XVII. A palavra quilombo é originária da língua banto 
umbundo e significa um tipo de instituição social, política e militar, conhecida na África Central, mais especificamente, na atual República Democrática do Congo (Zaire) e de Angola (MUNANGA, 2010). Esse termo umbundo confirma que é uma instituição constituída por um agrupamento militar de jovens guerreiros, composto pelos jaga ou imbangala (de Angola) e os lunda (do Zaire) (MUNANGA, 2010).

Os quilombos nos levam também ao Brasil do final do século XVI e aos séculos seguintes. Enquanto durou a escravidão institucionalizada, os quilombos (ou mocambos) se fizeram necessários para os escravos que fugiam das condições severas e desumanas do trabalho. Digno de nota são os quilombos do litoral do norte ao sul do país, especialmente nas áreas de plantações de cana-de-açúcar, arroz, cacau e nas armações baleeiras. No caso do litoral nordestino, destaca-se o Quilombo dos Palmares, que durou mais de 70 anos e se estendia além das províncias de Alagoas e de Pernambuco. Palmares foi liderado por mulheres e homens que, ora eram tratados como mitos, ora como personagens históricos, a exemplo de Aqualtune, Acotirene, Canga Zumba e Zumbi, sendo este último, o líder, assassinado após um ano da destruição do grande quilombo, em 20 de novembro de 1695 .

Esclarecendo melhor o que o quilombo significava para os negros fugidos, Nascimento (1980, p. 32) afirma que:

Quilombo é um movimento amplo e permanente que se caracteriza pelas seguintes dimensões: vivência de povos africanos que se recusavam à submissão, à exploração, à violência do sistema colonial e do escravismo; formas associativas que se criavam em florestas de difícil acesso, com defesa e organização socioeconômico - política própria; sustentação da continuidade africana através de genuínos grupos de resistência política e social.

Desde os anos 1950, intelectuais negros como Edison Carneiro, Clóvis Moura, Abdias Nascimento, Beatriz Nascimento, Lélia Gonzalez e Joel Rufino dos Santos, entre outros, apresentavam suas ideias acerca do tema em seminários, artigos, livros e filmes. Por meio dessas vozes, o quilombo se constituía como uma referência ideológica, cultural e política (NASCIMENTO, 1985). Revistando os escritos dos autores citados, encontramos vasta e variada produção acerca do quilombo que estava posto, em geral, como um fenômeno do passado. No entanto, vivia-se num contexto de "descoberta" de comunidades negras rurais em várias regiões do país (RATTS, 2003). 
As comunidades quilombolas contemporâneas (MOURA, 1987) recebem várias denominações, tais como "terras de pretos", "mocambos" e "comunidades negras rurais". Em um processo de mobilização, todas essas nomenclaturas convergiram para o termo "quilombo" ou "comunidade quilombola". Como decorrência desse processo de ressemantização, para o Estado brasileiro, o antigo quilombo foi metaforizado para a categoria "remanescente de quilombo" que, de certa forma, fortaleceu a ideia de grupo e não de indivíduo, ideia essa que é fundamental para ganhar funções políticas no presente, por meio de uma construção jurídica que permite pensar o futuro (ARRUTI, 2003).

\section{Comunidade Kalunga, imaginário e recepção das políticas públicas de educação e de saúde}

No centro do País, a pouco mais de $375 \mathrm{~km}$ de Brasília, vivem aproximadamente 5.000 pessoas em uma comunidade "encravada" nas encostas das montanhas do cerrado, constituindo a comunidade Quilombola Kalunga. Ela está localizada entre os municípios de Cavalcante, Teresina e Monte Alegre de Goiás, cujo território alcança cerca de 237.000 hectares, no estado de Goiás, compondo o território kalunga, hoje reconhecido como patrimônio histórico e cultural da humanidade. Está dividido em cinco núcleos, abrigando cerca de cinquenta grupos de base familiar: Vão de Almas, Vão do Moleque, Ribeirão dos Bois, Contendas e Kalunga. Conforme o mapa da Figura 1, pode-se localizar a cidade de Monte Alegre de Goiás e suas circunvizinhanças.

A comunidade Quilombola-Kalunga está situada na região do nordeste goiano, sendo uma das regiões mais pobres do estado de Goiás. Durante anos, os negros lutaram para que ocorresse um processo de construção identitária dos seus quilombos, vencendo o preconceito da cor da pele e buscando desmascarar a propaganda governamental de que as políticas públicas são iguais para todos os cidadãos e que conseguem alcançar todos os remanescentes quilombolas. São com as palavras da alma que o poeta Aimée Césarie, citado por Sartre (1960, p. 131), busca dar dignidade a esse povo, ao mesmo tempo em que se exalta a sua forma de ser negro:

Minha negritude não é uma pedra, surdez que é lançada contra o clamor do dia, Minha negritude não é uma catarata de água morta sobre o olho morto da terra. Minha negritude não é nem torre e nem catedral, ela mergulha na carne rubra da terra, ela mergulha na ardente carne do céu, ela perfura o opaco desânimo com sua precisa paciência. 


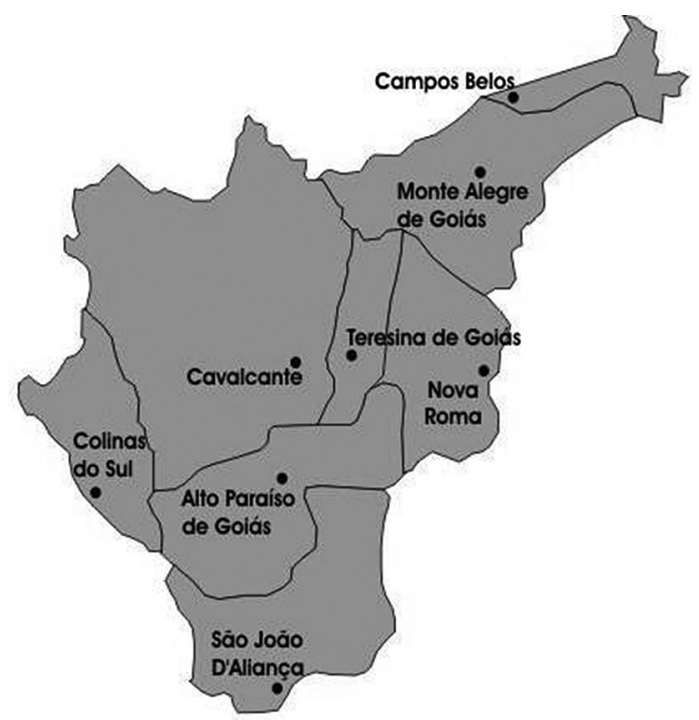

Fonte: Governo de Goiás (2013).

Figura 1. Quilombola-Kalunga: localização da cidade de Monte Alegre de Goiás onde está situada a comunidade.

Na Figura 2 temos a localização da comunidade Quilombola-Kalunga Riachão, onde foi realizada a pesquisa de campo.

Essas particularidades dos idosos afrodescendentes numa comunidade tradicional quilombola permitiram o uso da Teoria Antropológica de Gilbert Durand (1989), uma vez que o imaginário é um conjunto relacional de imagens que se formam na simbiose do interior (pulsões) e do exterior (pressões do meio cósmico e social). Vão nessa mesma linha as ideias de Gaston Bachelard (2001) de que o imaginário tem potência organizativa, pois tem a força para organizar os grupos e as ações de forma a desvelar esse imaginário.

Essa realidade observada e contada pelos idosos quilombolas mostrou que eles vivem carentes de educação e de saúde. Das políticas públicas ausentes na comunidade, nascem alguns questionamentos, entre eles: se elas condizem com a realidade vivida por eles; e se há interesse em materializar seus direitos que estão na legislação brasileira. $\mathrm{O}$ discurso captado nos desenhos, nos questionários e nas histórias relatadas mostra seus pensamentos, conforme Lefèvre e Lefèvre (2010, p. 112), relatam nessa passagem: 


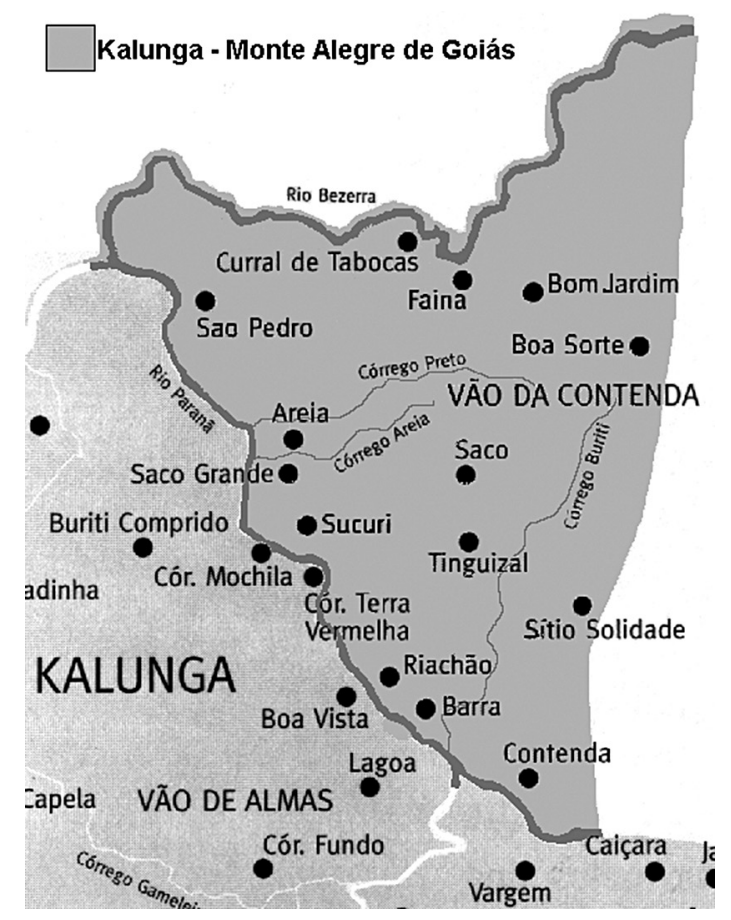

Fonte: BRASIL (2013).

Figura 2. Kalunga em Monte Alegre de Goiás.

Sabe-se que os pensamentos se dão sob formas discursivas, daí ser necessário estimular que as pessoas falem, discursem sobre o tema, o que permite captar um material rico, vivo, capaz de fornecer dados importantes que reconstruam o pensamento coletivo.

O viver dos idosos da comunidade, discorrido em frases e desenhos, está aquém da integração das práticas prioritárias em educação e em saúde dentro de uma política pública individual e coletiva. Nesse espaço de atuação, a equipe de saúde defronta-se com obstáculos de natureza político-institucionais e organizacionais, pois, geograficamente, encontra-se o maior desafio, disponibilizar a educação e a saúde pública à comunidade Quilombola-Kalunga. As serras e os caminhos inóspitos dificultavam as idas e vindas para a integração entre os cidadãos da cidade e da comunidade, do que se constata que as ações em saúde pública são oferecidas, apenas, na área de epidemiologia como vacinas nas datas das campanhas nacionais. 
A maioria dos idosos não demonstrou nenhum entendimento sobre o significado do que sejam políticas públicas. Apenas fizeram menção por meio de relatos, muitas vezes manifestando medo de represálias, por desconhecerem os seus direitos constituídos. A relação entre as três esferas governamentais e a participação da sociedade civil da comunidade Quilombola-Kalunga necessita ser repensada, pois as políticas não chegam em decorrência da falta de articulação, de estruturação e de funcionamento. Conforme relata Oliveira (2005, p. 53):

A análise da eficácia das políticas públicas nos países em desenvolvimento costuma girar entre os aspectos político-institucionais, financeiros e técnicos. Os aspectos políticos e institucionais, ou seja, a relação entre Estado e sociedade civil nos países em desenvolvimento não estão articulados e nem funcionando de maneira apropriada.

\section{Resultados e discussão}

O fato de a comunidade Quilombola-Kalunga ter permanecido distante dos centros urbanos, num lugar de difícil acesso e de poucas estradas, acabou fazendo deles um dos poucos exemplos de remanescentes negros que quase não sofreram influências externas em seu modo de vida, preservando, dessa maneira, sua tradição e cultura. Dentro do território kalunga, só se consegue alcançar os lugares a pé, em lombo de mula ou de canoa, de camionete com tração até chegar ao "Riachão", centro da comunidade. E assim, está sendo feito há quase 300 anos; as distâncias são vencidas pelas necessidades de sobrevivência.

A pesquisa foi realizada com dez idosos dessa comunidade, pertencentes à etnia negra, sendo cinco homens e cinco mulheres. Para preservar o anonimato, foram-lhe atribuídos pseudônimos, nomes de dez árvores típicas da região do cerrado, como forma de prestigiar a natureza com a qual eles convivem diariamente. Ao mesmo tempo, algumas vezes, as plantas foram e são utilizadas como resposta aos pedidos de socorro, pois a natureza tem sido a única garantia de sobrevivência desses idosos que não podem usufruir de políticas públicas em educação e em saúde. O Quadro 1 mostra os pseudônimos, idade e gênero dos idosos pesquisados.

Os dados primários da pesquisa foram obtidos por meio de bases teóricas de Gilbert Durand, com a realização do teste AT-9 de Yves Durand. Já os dados secundários foram obtidos em documentos, livros, artigos científicos e revistas especializadas, de forma a se obterem os dados e a discussão que se seguem abaixo. 
Quadro 1. Dados dos entrevistados.

\begin{tabular}{|l|c|c|c|}
\hline No $^{\mathbf{2}}$ & Pseudônimo & Idade & Gênero \\
\hline 01 & Sucupira & 63 anos & Feminino \\
\hline 02 & Amburana & 72 anos & Feminino \\
\hline 03 & Araçá & 84 anos & Feminino \\
\hline 04 & Quaresmeira & 74 anos & Feminino \\
\hline 05 & Aroeira & 78 anos & Feminino \\
\hline 06 & Pau D'Óleo & 79 anos & Masculino \\
\hline 07 & Tinguinal & 72 anos & Masculino \\
\hline 08 & Ipê & 77 anos & Masculino \\
\hline 09 & Jacarandá & 64 anos & Masculino \\
\hline 10 & Gonçalo & 68 anos & Masculino \\
\hline
\end{tabular}

Fonte: Elaborado pelos autores (2013).

Os resultados da pesquisa mostraram a divergência entre o imaginário internalizado da comunidade Quilombola-Kalunga e a construção subjetiva das demandas cidadãs em torno dos direitos à saúde e à educação. $\mathrm{O}$ verbo imaginar conduz os sujeitos idosos para esse devaneio humano do seu mundo histórico, cultural e afrodescendente. Esclarecendo o imaginar, Bachelard (2001, p. 3) afirma que é um lançamento psíquico em busca de uma nova perspectiva de vida ao afirmar que "[...] imaginar é ausentar-se, é lançar-se a uma vida nova", ou ainda, que "[...] as imagens são, do nosso ponto de vista, realidades psíquicas. Em seu nascimento, em seu impulso, a imagem é, em nós, o sujeito do verbo imaginar. Não é o seu complemento. O mundo vem imaginar-se no devaneio humano" (p. 14) e, finalmente, que "[...] imagem é deduzida do movimento" (p. 95).

No trajeto antropológico descrtio, os idosos exteriorizaram o imaginário em seu dialeto, nas histórias de vidas e nos desenhos representados das imagens pictográficas dos nove elementos. Eles narraram a história do desenho, por meio de sua exteriorização em imagens.

No Quadro 2, a seguir, apresenta-se uma síntese dos resultados encontrados a partir da análise do teste AT-9. Esse Quadro é fruto das análises dos desenhos e das histórias narradas pelos entrevistados, que permitem desvelar o imaginário e classificar o microuniverso mítico deles.

Para Loureiro (2004, p. 13), que se dedica ao estudo do teste AT-9 de Yves Durand, é importante ressaltar que: 
O instrumento que permite o desvelamento do imaginário e o desenho do mapa das imagens, das representações mentais, do traçado da paisagem mental dos grupos, está impregnado de características específicas que vetorizam a identidade intrínseca do grupo, cuja interioridade é atingida, pelo teste, em sua simbiose com o cultural, com o externo, e decodificada e classificada, conforme as estruturas antropológicas do imaginário.

Declarados por meio dos movimentos das imagens coletadas por esta pesquisa, esses relatos ocorrem com maior evidência nos imaginários dos idosos, mediante tabulação e identificação dos microuniversos míticos encontrados nos dez sujeitos idosos entrevistados: cinco do gênero feminino e cinco do gênero masculino, habitantes da comunidade Quilombola-Kalunga. O universo mítico do grupo revela a sua paisagem mental, conforme explicita Loureiro (2004, p. 53):

Paisagem mental é entendida como a maneira peculiar de cada grupo atuar, aceitar ou rejeitar isto ou aquilo, é o que direciona a construção do mundo para cada grupo. As paisagens mentais são basais no entendimento na percepção, comunicação e formas de organização do grupo.

Percebe-se, no Quadro 2, os seguintes resultados de classificação dos sujeitos idosos da comunidade Quilombola-Kalunga: casos em que são evidenciados dois sujeitos, os de números 07 e 10, com maior índice de desestrutura no seu imaginário;casos que são sequenciais: três sujeitos, os de número 01, 02 e 05; o caso de imaginário pseudodesestruturado (com fraca estrutura): o sujeito número 02; o caso do imaginário pseudodesestruturado, que apresenta tendência mística: o sujeito número 05 ; os sujeitos com Imaginário pseudodesestruturado, com detalhes a identificar uma tendência sintética disseminatória: os de números: 0304 e 09, todos os três com Estrutura Disseminatória (harmonização dos contrários, uma síntese de heroísmo com antifrásia, sintética/ disseminatória/dramática). O de número 09 é considerado DUEX, por ter Imaginário Disseminatório e Diacrônico (o primeiro rejeita esquisomorficamente e depois acolhe misticamente, postado no regime noturno das imagens). O sujeito de número 08 possui Imaginário com Estrutura mística impura, enquanto o de número 06, possui Imaginário com Estrutura Mística.

Assim se apresentaram os dez microuniversos míticos emergidos dos sujeitos do teste, deixando ver em cinco dos sujeitos a falta de estrutura como predominante. A segunda estrutura identificada foi a disseminatória, pois quando o heroísmo 


\begin{tabular}{|c|c|c|c|c|c|c|c|c|c|c|c|}
\hline & 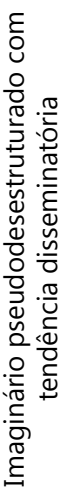 & 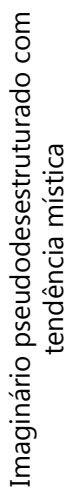 & 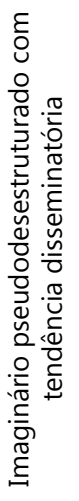 & 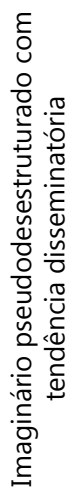 & 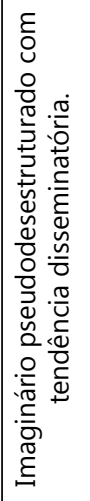 & 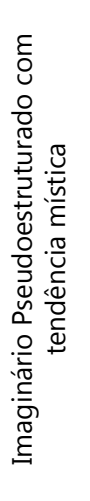 & 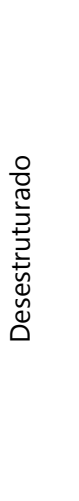 & 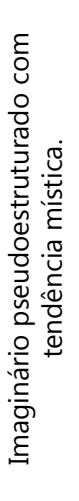 & 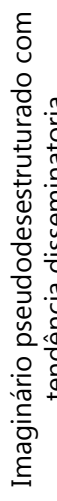 & & 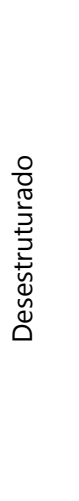 \\
\hline & $\begin{array}{l}\frac{\pi}{0} \\
\frac{0}{0} \\
\frac{0}{\pi} \\
\frac{\pi}{\pi} \\
\frac{T}{4}\end{array}$ & 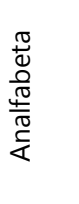 & 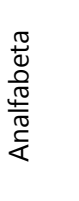 & 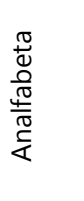 & 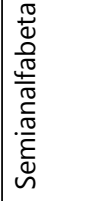 & 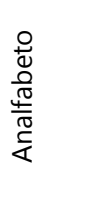 & $\begin{array}{l}\frac{0}{ \pm} \\
\frac{0}{0} \\
\frac{\pi}{\frac{1}{\pi}} \\
\frac{0}{4}\end{array}$ & 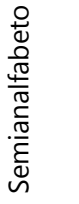 & $\begin{array}{l}\frac{0}{4} \\
\frac{0}{0} \\
\frac{0}{\sqrt[T]{\frac{1}{\pi}}} \\
\frac{0}{4}\end{array}$ & & 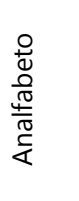 \\
\hline & 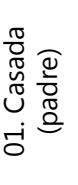 & 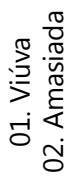 & 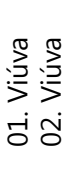 & 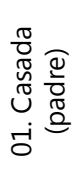 & $\begin{array}{l}\stackrel{0}{3} \\
\text { iं } \\
\text { - }\end{array}$ & 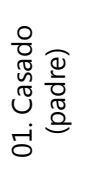 & 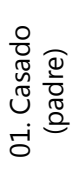 & 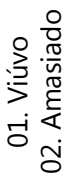 & $\begin{array}{l}\stackrel{0}{3} \\
\text { ì } \\
\text {-ं }\end{array}$ & 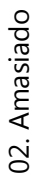 & 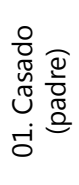 \\
\hline & 6 & N & $\aleph_{\infty}$ & ホ & $\stackrel{\infty}{\wedge}$ & হ & $\stackrel{\operatorname{Ln}}{\wedge}$ & $\stackrel{\bullet}{\wedge}$ & \multicolumn{2}{|l|}{ นُ } & $\vec{\gamma}$ \\
\hline & غ் & 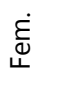 & $\begin{array}{l}\dot{\Xi} \\
\stackrel{\varpi}{山}\end{array}$ & 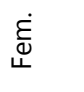 & 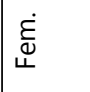 & 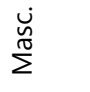 & $\begin{array}{l}\dot{W} \\
\stackrel{\pi}{\Sigma}\end{array}$ & $\begin{array}{l}\dot{y} \\
\stackrel{\tilde{J}}{\Sigma}\end{array}$ & \multicolumn{2}{|l|}{$\begin{array}{l}\dot{y} \\
\stackrel{\tilde{\pi}}{\Sigma}\end{array}$} & $\begin{array}{l}\dot{W} \\
\underset{N}{\Sigma}\end{array}$ \\
\hline & $\begin{array}{l}. \frac{0}{2} \\
\frac{\partial}{3} \\
\text { ڤ }\end{array}$ & 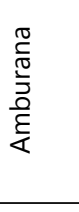 & $\underset{\frac{\pi}{2}}{\frac{\pi}{4}}$ & 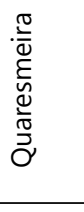 & 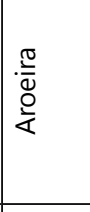 & 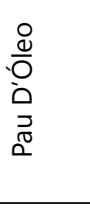 & $\begin{array}{l}\bar{N} \\
\stackrel{N}{\bar{N}} \\
\stackrel{D}{=} \\
i=\end{array}$ & $\stackrel{\leftrightarrow}{\varrho}$ & \multicolumn{2}{|l|}{$\begin{array}{l}\frac{\pi}{0} \\
\frac{1}{\pi} \\
\frac{1}{0} \\
\frac{0}{\pi} \\
\frac{\pi}{2}\end{array}$} & 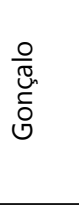 \\
\hline & - & ऽ & ஜ & ১ & $\stackrel{2}{\circ}$ & ๑ & ô & $\stackrel{\infty}{\circ}$ & \multicolumn{2}{|l|}{ g } & 유 \\
\hline
\end{tabular}


aparece, ele surge como impureza na estrutura mística encontrada em dois sujeitos ou perfazendo a síntese. Nenhum idoso apresentou imaginário heróico, o que condiz com os resultados da pesquisa de Yves Durand (1988) que afirma que, dificilmente, o heroísmo aparece no imaginário de idosos. O autor detectou que o heroísmo se encontra mais comumente no imaginário dos jovens.

Pode-se ver que a visão de mundo - o pensar, o sentir e o agir - expressa pelos idosos condiz com o imaginário detectado de cada um do grupo. A maneira truncada da linguagem dos componentes do grupo leva a identificar a dificuldade de ajustamento na sociedade atual, na comunidade onde eles têm o seu mundo.

Quando faltam ações para realizar políticas públicas, como acontece nessa comunidade, eles não se veem com perspectivas e se apegam à família, à natureza, à fé e à religiosidade. Essa ação homogeneizadora de monocultura/pedagógica $\mathrm{e}$ sistêmica favorece a pedagogia da "chibata oculta", diminuindo o desejo e os sonhos de viver desses idosos, conforme a fala de um deles: "Se tivesse escola no meu tempo, as coisas seriam diferente... se tivesse um estuduzinho, eu saberia mais o que fazer com o povo de fora. É difícil ir só pra cabeça" (Aroeira). Faz-se urgente e necessário construir e inserir ações pedagógicas para dar suporte intelectual e social a essa comunidade a fim de despertar o interesse acerca dos direitos deles, para que possam romper com o medo por meio das práticas educativas e construir currículos estruturados e direcionados à população tradicional, principalmente para a clientela de idosos que vive à mercê da espera. Os Parâmetros Curriculares Nacionais reforçam essa discussão:

É sabido que, apresentando heterogeneidade notável em sua composição populacional, o Brasil desconhece a si mesmo. $\mathrm{Na}$ relação do país consigo mesmo é comum prevalecerem vários estereótipos, tanto regionais quanto em relação a grupos étnicos, sociais e culturais [...]. Historicamente, registra-se dificuldade para se lidar com a temática do preconceito e da discriminação racial/ étnica. O país evitou o tema por muito tempo, sendo marcado por "mitos" que veicularam uma imagem de um Brasil homogêneo, sem diferenças, ou em outra hipótese, promotor de uma suposta "democracia racial". (BRASIL, vol. 10, p. 22, 1997).

Faz-se necessário que a cultura e o multiculturalismo sejam os eixos prioritários para suprir os déficits em que vivem os idosos quilombolas, numa grande carência em educação sistemática e falta de informações que possam contribuir de forma positiva para a formação da identidade e da alteridade. Como reforça Perez Gómez (2001, p. 54): 


\begin{abstract}
A escola deve ser concebida como um espaço ecológico de cruzamento de culturas, cuja responsabilidade específica que a distingue de outras estâncias de socialização e lhe confere identidade e relativa autonomia é a mediação reflexiva daquelas influências plurais que as diferentes culturas exercem de forma permanente sobre as novas gerações.
\end{abstract}

Essa negação da oferta em educação e em saúde pública diminui a perspectiva do que é imprescindível ao ser humano: a preservação da vida. Sem educação e saúde, vive-se no escuro, conforme declara uma das entrevistadas que enxerga pouco e não faz uso de óculos, que poderia auxiliá-la em alguma atividade. Além dessa dificuldade, ela também é analfabeta e não quer estudar, alegando não ter "mais vista" (visão) "e nem idade" para isso, desejando, ao final do dia, apenas chegar a casa, tomar banho, jantar e dormir, para a lida do outro dia: "De dia, eu enxergo pouco, e de noite, nada" (Tinguizal).

O viver dos idosos da comunidade Quilombola-Kalunga está aquém da integração das práticas prioritárias em educação e em saúde pública individual e coletiva. Nesse espaço de atuação, a equipe de saúde defronta-se também com obstáculos de natureza político-institucionais e organizacionais, conforme relato das necessidades dos idosos, declarado pelo agente comunitário de saúde: "Consulta pelo menos de dois em dois meses, é o que mais pretendia... É preciso ter pelo menos um posto de saúde, mas já estamos cansados de tanto falar. Eu fico com medo de falar, mas tem que falar a verdade". Esse medo de falar faz com que a comunidade permaneça sem reivindicações, sendo que seus líderes comunitários continuem também sem nenhuma ação na busca por serviços públicos. As participações dos líderes comunitários em reuniões abertas são verdadeiras demonstrações de timidez e de acanhamento, pois permanecem sem palavra para solicitar ou exigir qualquer um dos seus direitos.

Continuam sem voz para exigir o cumprimento dos seus direitos como cidadãos, permanecendo tímidos, acanhados e sem nenhuma fala de reivindicação. Aqui o silêncio fala alto, como se nada precisasse de mudança na comunidade. Quando participam de reuniões abertas, ficam sem palavras para solicitar ou exigir os seus direitos; ou quando relatam algo sobre o fracasso das políticas públicas, nota-se um medo quase pueril, como se estivessem fazendo algo errado. Ficam alheios à liberdade democrática de expressão e não percebem que essa falta de expressão é uma herança da história cultural e étnico-racial dos seus ancestrais. Verificou-se que esses cidadãos ainda permanecem sem nada reivindicar, sem nenhuma ação na busca por serviços públicos, ficando apenas no desejo: “Uá! Eu queria que assim 
que ter um tratamento, ter um posto de saúde. [...] Tem deles que tem dinheiro prá paga frete e vir pro hospital. Quando não tem, toma emprestado e vai ao menos trabalhar prá paga" (Ipê). Ao falar do multiculturalismo revolucionário, McLaren (2000, p.88) pontua que é necessário mudar esse quadro para que a realidade intercultural seja modificada: "[...] o refazer do social e a reinvenção do eu precisam ser compreendidos como dialeticamente sincrônicos [...] são processos que se informam e se constituem mutuamente".

Quando não se têm recursos à disposição, o jeito é recorrer ao que está mais acessível. No caso da falta de médicos, os que podem, recorrem ao curandeiro, conforme relata Araçá: "Eu levei o marido no curador; o curador fica no Rio Corrente, na divisa com o Municipio de Cavalcante-GO. Se sai agora chega lá de noite. É longe! O curador passou remédio!" Essa comunidade busca ajuda não somente na natureza, como também na fé. Eles recorrem aos curandeiros da região do Kalunga em busca de uma solução para eliminar as doenças e também as mordeduras de cobra: "Agora a cobra é um animal muito perigoso. Se ela pegar qualquer vivente e não cuidar com remédio rápido, o vivente morre. Ela é muito venenosa". (Pau D'Óleo). Assim vemos que o medo predomina na comunidade quilombola. Seus habitantes chegam mesmo a sentir medo das "pedras", da "onça" e da "cobra": elementos que surgiram nos desenhos e que são símbolos da falta de heroísmo. Acostumados a não se manifestarem ao longo da história, parece que assim querem permanecer, pois sentem que seu lugar no mundo já está "preestabelecido". O medo da morte é entendido de forma ampliada com os percalços da vida, aflorando nas interações frágeis com as autoridades que ali conseguem, ou se dignam a chegar. Misticamente assumem sua condição e deixam ver a desestrutura do seu imaginário aflorar.

No contexto da educação e da saúde, tão importantes na vida desses cidadãos, é o desejo de ler, de escrever e de contar que permanece latente nos relatos dos idosos afrodescendentes, aqui representado pela fala de Araçá: "Quando eu era pequena tinha muita vontade de escrevê, pegava um pedaço de pau que soltava tinta e riscava o papel". Diante desses resultados, nota-se a importância da alfabetização que é dado por Araçá e o grande desejo de que seus filhos e netos adquiram vagas em instituições educacionais que lhes garantam o direito à educação, que não foi oferecido aos seus antepassados. Direito esse que deverá ser repensado na atualidade, pelo seu valor, como forma de garantir aos mais jovens o acesso às escolas e às universidades.

As cotas nas universidades brasileiras são um exemplo de como esses direitos podem ser resgatados, pois sem esse tipo de ação de intervenção, os Quilombolas-Kalunga 
ficarão à mercê da natureza, sem condições de concorrerem com os cidadãos de outras culturas. Faz-se necessário, então, libertá-los das "correntes" da ignorância, oferecendo-lhes uma educação sistematizada, para que possam fazer as próprias escolhas, adquirir voz e possibilidades iguais a das políticas públicas interculturais que levem em conta o multiculturalismo existente no Brasil, de acordo com a fala de outra moradora da comunidade: "A minha filha é educada, gosto dela, zelosa com Deus e tudo. Todo mundo gosta dela e ela também estudou nessa escola aqui e aprendeu. Tudo eu preciso, né? A neta e a professora é a mais importante" (Aroeira). A Constituição Federativa do Brasil dá segurança legal aos direitos individuais e coletivos a todos os brasileiros, mas, infelizmente, ela não está sendo usada para implementar políticas públicas em educação e em saúde na comunidade Quilombola-Kalunga. As leis estabelecidas identificam, representam e revelam diversas possibilidades dentro do contexto do multiculturalismo e das relações sociais dos grupos étnico-raciais da cultura afro-brasileira, consoante à fala de Gonçalo:

Eu queria mesmo era um posto de saúde prá quando adoecer um, ter remédio pra salvar um doente. Eu mesmo fui mordido de cobra duas vezes. Fiquei aqui no kalunga e tomei o contra veneno. O contra veneno é um negócio que coloca no copo um pó... mas se quiser mais forte pode também colocar pinga.

Essa falta de políticas públicas, em pleno século XXI, para os kalungas, percebida nas entrevistas com os idosos, mostra que há uma acomodação e uma estagnação diante a vida. O que mais causa dor em um cidadão idoso e negro: a chibata na carne dos seus ancestrais ou a ausência das políticas públicas que desrespeita o direito universal à vida?

Pinsky e Pinsky (2010) relatam o que se pode esperar do Estado: a defesa e a proteção da vida de todos os cidadãos, o direito à vida, à liberdade, à propriedade, à igualdade perante a lei. Caso contrário, o Estado é omisso no seu papel.

O relato de um dos entrevistados mostra o descaso da falta de políticas públicas: "Eu tô com dor desde que tinha 40 anos. Dor no joelho, nas duas pernas. Ano passado pra cá, tô com água no pé. O pé fica dormente e eu já tomei muito remédio de mato na pinga, são remédios caseiros". (Aroeira)

A Constituição Brasileira garante a obrigatoriedade do voto a partir dos 18 anos e a não obrigatoriedade, a partir de 65 anos. Mesmo que o voto não seja obrigatório, os idosos cumprem seu dever cidadão e democrático, religiosamente, votando 
como se o dia das eleições fosse um dia sagrado, elegendo candidatos em todas as instâncias: federal, estadual e municipal, com espírito aberto e voluntário, como se nesse exato momento, ao inserirem seu voto na urna, visualizassem a realização dos seus desejos e direitos de cidadania igualitária e justa, exaltado na fala de um dos idosos, como faz Tinguizal: "Todo mundo vem cá e promete e depois vá embora. [...] não sei escrevê, fazê, eu não sei fazê, tenho a mão dura... Não dou conta não. [...] eu nunca estudei, eu não fui na escola. Eu não tenho tempo". A comunidade Quilombola-Kalunga aguarda um tratamento de igualdade feito pelos poderes de distribuição das políticas públicas; esperam fazendo uso da fé e cumprindo seus deveres de cidadania. Sobre a necessidade de saúde, Gonçalo afirma:

Num ponto de rapidez não tem saúde, esses dias mesmo, nós saímos na base das nove horas do dia e chegamos ao meio dia. Tava passando muita mal. E Araçá continua: [...] Eu tô ruim até prá enxergar! Eu não sei fazer desenho, eu quero fazer uma gente, mais não sei como fazer o pé.

A necessidade de políticas públicas que abranjam de forma cultural e intercultural deve estar incluída no contexto multicultural dessa comunidade como resgate humano. Como cita Torres (2001, p. 196) “[...] o multiculturalismo é uma orientação filosófica, teórica e política que não se restringe à reforma escolar e que aborda o tema das relações de raça, sexo e classe na grande sociedade". Esse fato nos remete a uma abrangência que vai além dos direitos estabelecidos, que rompe com qualquer tipo de discriminação e opressão, caracterizada por ações políticas eficazes e afirmativas, e que vence as diferenças existentes em nosso meio.

Precisa-se comprometer com a necessidade de resgate do valor do "outro", que se dá com o imperativo de implementar as políticas públicas interculturais, que faz acontecer o multiculturalismo, como resgate da identidade cultural, conforme anota um dos idosos: "No meu tempo de meninota não tinha escola. Não tenho vontade mais de estudar. Estou um bagaço, velha, trabalho demais. Não quero não. Não dá para mim não". (Gonçalo). O desejo por conhecimento e por autoestima precisa ser resgatado em uma constante dinâmica de construção de diferentes modos de viver no contexto cultural específico das populações tradicionais da comunidade Quilombola-Kalunga, uma vez que a educação formal é primordial e fundamental para aumentar a qualidade de vida dos idosos: "Vou estudar agora, pois quando era pequena, foi dificil aprender" (Amburana). Assim, entendemos que o desejo por conhecimento e a autoestima precisam andar juntos, pois a falta de um compromete a outra. A cultura do silêncio dos idosos em decorrência da 
ausência de uma educação sistematizada fica explícita na declaração de Araçá: "Na minha vida eu nunca fui à escola, não no meu tempo não tinha não!".

Uma educação que não foi oferecida no passado contribuiu significativamente para que, na atualidade, esses idosos não tenham conhecimentos e objetivos para proverem e que possam suprir suas necessidades básico-primárias de sobrevivência humana: "Uá! Eu queria que assim que ter um tratamento, ter um posto de saúde. [...]. Tem deles que tem dinheiro prá paga frete e vir pro hospital. Quando não tem, toma emprestado e vai ao menos trabalhar prá paga" (Ipê). Conhecer a cultura da comunidade Quilombola-Kalunga e estruturar ações afirmativas para garantir e disponibilizar políticas públicas em educação e saúde de forma sequencial, lógica e contínua poderão servir de base para mudar a realidade desses idosos e não permitir que a vida seja muito difícil, como relata Jacarandá: "É duro. É difícil. Agora tá bom! Antigamente era na rede, descia carregando na rede, agora tem carro alugado... Mas, prefeitura não adianta confiar...” Dessa forma, o paradigma da cidadania e do respeito ao multiculturalismo é de ações voltadas à dignidade humana das populações tradicionais que não têm acesso às políticas públicas em educação e em saúde. Elas poderão ser oferecidas e compartilhadas por meio da lei estabelecida pelo Estado de Direito, pela equidade e a igualdade. É essencial rever o estado de vida desses cidadãos idosos para uma estruturação e para a construção eficaz de ações políticas públicas e interculturais que valorizarão o multiculturalismo.

Bachelard (2003, p. 89) afirma ser “[...] impossível escrever a história do inconsciente humano sem escrever uma história da casa". Na fala de um dos sujeitos pesquisados e nas suas representações pictóricas e semânticas, o mundo interior de sua casa manifesta o desejo de transformar o interior latente para o exterior patente. A casa é algo mais que o ambiente de moradia; é uma representação de seu refúgio e motivo de orgulho. Para a mulher kalunga, a casa representa o repouso quieto do lar, a afirmação de um mundo finalmente adquirido, e a certeza de que ali sua prole poderá ter algum futuro, longe das incertezas e das intempéries de ter a quem foi negado e ter que se submeter à perda como direito dos seus ancestrais: "[...] $a$ minha casa é meu refugio, porque ela é boa tem os cômodos bons. Gente tem casa boa fica satisfeita, antes era de palha agora é de telha" (Sucupira).

Sucupira demonstra medo, mas teme usar a espada, então não mata a cobra, como exposto em seu desenho. O elemento espada está representado e simbolizado na utilidade e não ataque ou defesa. A ponta da espada está direcionada para baixo - o que suaviza a possibilidade heroica: "A espada corta a carne, o pau o que tem precisão ela corta, corta a carne, laranja, faz tudo". Sendo a serpente o símbolo máximo dos atributos de traição, perfídia, queda e danação da espécie 
humana, na afirmação judaico-cristã, em nenhum momento a serpente foi vista pelo entrevistado como símbolo corporificado do desejo, ou como elemento portador da capacidade regenerativa ou mesmo da cura. Para a comunidade local, o perigo mora na figura das serpentes, entre outros bichos peçonhentos, os quais encarnam o poder terriomórfico de reduzir o homem ao mundo caótico por ação da morte, que Loureiro (2000) se refere ao porvir da morte alienada.

\section{Conclusão}

Ao pesquisar as políticas públicas para educação e saúde para os remanescentes Quilombolas-Kalungas, particularmente os idosos, deparou-se com situações bastante particulares. Na tentativa de desvelar as imagens mítico-simbólicas, valeu-se, no trabalho, das teorias de Gilbert Durand (1989) e do teste AT-9 de Yves Durand (1988), para relacioná-las com as políticas públicas em educação e saúde, de forma que sejam interculturais e consigam atender às exigências do multiculturalismo. Os idosos afrodescendentes não se sentem contemplados dentro dessa visão multicultural das atuais políticas públicas em educação e saúde. Aliás, eles ainda não alcançaram uma consciência cidadã que os permita valorizar tais políticas. Há uma estagnação das reivindicações dos idosos, frente a um silêncio imperativo dessa comunidade.

A investigação trouxe à tona a realidade vivenciada pelos idosos da comunidade Quilombola-Kalunga: a não concretização e a ausência das políticas públicas, além da constatação de subalternidade internalizada no silêncio, na baixa-autoestima constatada na realidade, o que não condiz com as necessidades básicas de sobrevivência de um ser humano. Eles se sentem desprovidos da oferta de saúde e de uma educação sistemática no contexto dos direitos democráticos e culturais. Eles estão no sentido contrário do caminho que estão percorrendo para legitimar a cidadania. Constatado por meio desta pesquisa, com o emergir do passado, as raízes dos seus ancestrais estão sendo oferecidas pelas políticas públicas na lida desumana presente da não oferta desses serviços públicos.

Se não existe uma eficácia no direcionamento das políticas públicas nos países em desenvolvimento, como o Brasil, o que se esperar em uma comunidade tradicional como a Quilombola-Kalunga? E com o aumento de envelhecimento crescente no Brasil, com suas desigualdades e especificidades multiculturais, como atender à especificidade dessa comunidade?

A meta desta pesquisa não foi somente levantar questionamentos para fazer vir à tona a inexistência de políticas públicas para os idosos, mas sim contribuir para o prolongamento da vida, mantendo a capacidade funcional do idoso, disponibilizando recursos e condições para que eles sejam autônomos na busca de suas realizações, 
pelo maior tempo possível de suas vidas, com qualidade, rompendo com ações e hábitos errôneos em decorrência da falta das políticas públicas.

O idoso pode ter hábitos arraigados, mas a intensa experiência de vida pode torná-lo adaptável ao viver de novas situações. Para essas adaptações, é preciso vivenciar novas situações, acumular experiências que possam ser extremamente valiosas. Uma dessas adaptações é a busca pela alfabetização, porque a sua falta prejudica a autonomia e a condição de decodificação individual do letramento e a busca para fazer valer os seus direitos. A falta de uma educação sistematizada, não oferecida no passado aos idosos, reflete-se hoje nas consequências de sobrevivência inadequada e na qualidade de vida precária.

As políticas públicas inseridas no multiculturalismo e as necessidades interculturais nos fazem refletir sobre a cultura dessa comunidade sob o ponto de vista da educação e da saúde. Por um lado, é um desafio enorme a questão sobre a aquisição de conhecimentos sistemáticos e, por outro, a continuidade no sistema de cuidados e de prevenção da saúde, essenciais para se estabelecer uma condição de vida digna. Acredita-se que, para acontecerem políticas públicas em educação e saúde é indispensável ter informação e conscientização da realidade desses cidadãos em sua comunidade, para que haja um resgate social de direitos humanos para a equidade em cidadania.

Nossos sentidos, diante das condições humanas podem estagnar a nossa compreensão dos "outros", como algo distante e comum nas relações diárias. Portanto, é importante promover processos educacionais e de saúde pública que permitam que identifiquemos o valor do "outro", a fim de não cometermos os mesmos erros do passado, para a submissão dos idosos das comunidades tradicionais na sociedade contemporânea.

O multiculturalismo revolucionário se impõe ao capitalismo, lutando para a libertação independentemente de raça e de gênero, exaltando as relações de poder na sociedade e na cultura, indo, dessa forma, além da tolerância por uma política de respeito a intervenções e a afirmações positivas para a busca da qualidade de vida para os idosos, deixando essa ausência de políticas públicas em educação e em saúde como se fosse uma falta natural para os negros.

Essa falta de políticas públicas tratada com naturalidade no contexto dessa comunidade leva a caminhos opostos em relação ao interculturalismo e ao multiculturalismo. Ao reconhecer a totalidade, o multiculturalismo crítico não desconsidera a classe social como categoria, tendo em vista a manutenção do comprometimento dos estudos multiculturais com o questionamento das desigualdades sociais, que não são secundarizadas em função das diferenças 
culturais. Defende, portanto, o engajamento de uma educação que esteja embasada em uma teoria textual, social e histórica.

Quando se fala em políticas públicas em educação e em saúde para um grupo de idosos afrodescendentes, os gestores desfocam o assunto e logo ressaltam a política partidária, apresentando-se como aqueles que irão introduzir essa ação. Primeiramente, serão necessárias informações e conscientização de uma política voltada ao resgate social de direitos humanos para a equidade em cidadania garantida por lei e romper com a política assistencialista e clientelista existente.

Os kalungas vivem em sintonia com a natureza e se completam com ela. A simbiose com a natureza é percebida quando eles aguardam pelo sinal da natureza, para poderem fazer uso dela, na busca por raízes e plantas que curam doenças comuns, e pela qualidade de vida e de sobrevivência que ela proporciona. $\mathrm{O}$ idoso precisa vencer não só a hostilidade da natureza, mas também a hostilidade social e política. É um mundo hostil que precisa ser percebido também na falta de políticas públicas, na corrupção das autoridades políticas que massacram direitos e privilegiam algumas pessoas em detrimento de outras. Os idosos afrodescendentes permanecem abandonados, sem nenhuma ação política que atendamàs suas necessidades. Nos relatos, eles comentam de suas necessidade, mas, infelizmente, em nenhum momento das entrevistas ocorreu uma fala forte na defesa dos seus direitos junto aos órgãos públicos.

Dessa forma, faz-se necessária uma educação direcionada aos idosos da comunidade Quilombola-Kalunga que seja integradora nas ações pedagógicas de políticas públicas em educação e em saúde, discutidas por meio de uma dialógica multidisciplinar, contextualizando o multiculturalismo, como fator primordial em uma luta pela construção da democracia e de um estado democrático, reconhecendose como autor-autônomo e valorizando-se em seu contexto cultural.

O que se constatou neste texto foi a cultura do receio de exigir políticas públicas para educação e saúde, devido ao medo de reinvindicar seus direitos, que ficaram durante muito tempo enraizados e, em contrapartida, une-se com a falta de interesse dos gestores. Essa cultura foi sendo aos poucos legitimada por meio da história, quando, no passado, os ancestrais perpetuaram esses receios que se apresentam no presente com roupagem diferenciada. Como se o viver sem direitos, fosse uma fatalidade ou mesmo um destino! Há quinhentos anos, os cidadãos da época não tinham consciência do valor humano e das leis constituídas aos cidadãos negros que hoje temos em pleno século XXI. Sendo que um dos fatores dessa falta de direito é de estar localizado geograficamente numa das regiões mais pobres do estado de Goiás, que é o nordeste goiano, onde a população vive em constante busca de políticas públicas eficazes. 


\section{Representational images, public policies, and health education in an imaginary group of elderly community Quilombola-Kalunga de Monte Alegre de Goiás}

\section{Abstract}

The theories of the imagination of Gilberto Durand and the AT-9 Test of Yves Durand allow raise individual and group images. This survey was conducted through unstructured interviews on the imagination of a group of elderly individuals in the Quilombo-Kalunga community in Monte Alegre de Goiás (Brazil). The interviews also concerned public policies of education and health, which can provide these elderly people with better living conditions. It is known that public policies'supply and control guidelines in education and health are transcribed in the Brazilian Constitution of 1988 and the Statute of the Elderly (Law no. 10.741/2003), but they do not effectively reach Brazil's most remote locations. The research report seeks to demonstrate that along with the Kalunga culture of silence is governmental omission and patronage, leaving the population without education and health services.

Keywords: Imaginary. Elderly of the community Quilombola-Kalunga. Public politics. Education and health.

\section{Imágenes de representaciòn de las políticas públicas de la educación y salud, en el imaginario de un grupo de ancianos de la comunidad Quilombola-Kalunga de Monte Alegre de Goiás}

\section{Resumen}

Teorias del Imaginario Durand Gilberto (1989) y la prueba AT-9 Yves Durand (1988), proporcionan herramientas para elevar fotos individuales y grupales de la comunidad Quilombo mayor Kalunga en Monte Alegre de Goiás, Brasil, para alcanzar a las políticas públicas de educación y salud y mejorar la calidad de vida de las personas mayores. La alimentación y el control de las políticas públicas en educación y salud se transcriben en la Constitución de 1988 y el Estatuto de las Personas de Edad (Ley $N^{\circ}$ 10.741/2003), sin embargo, no llegan efectivamente a los lugares más remotos del país. El texto tiene como objetivo demostrar que en la cultura de Kalunga, la omisión de los poderes públicos y el clientelismo hacen que esta población no sea atendida en la educación y la salud.

Palabras clave: Imaginario. Comunidad ancianos Quilombola-Kalunga. Políticas públicas y educación para la salud. 


\section{Referências}

ARRUTI, J. M. P. A. O quilombo cinceitural: para uma sociologia do "artigo 68": texto para discussão do projeto Egbé-Territórios Negros. Rio de Janeiro: Koinonia, 2003.

BACHELARD, G. A terra e os devaneios da vontade: ensaio sobre a imaginação das forças. 2. ed. São Paulo: Martins Fontes, 2001.

. A terra e os devaneios do repouso: ensaio sobre as imagens da intimidade. São Paulo: Martins Fontes, 2003.

BRASIL. Constituição Federal de 1988. Brasília, DF: Senado Federal, 2001. . Lei $n^{\circ} 10.741$, de 01 de outubro de 2003. Dispõe sobre o Estatudo do idoso e dá outras providências. Diário Oficial da União, Brasília, DF, 3 out. 2003.

BRASIL. Ministério de Educação. Secretaria de Educação Fundamental. Parâmetros curriculares nacionais. Brasília, DF: Ministério da Educação, 1997.

. Uma história do povo Kalunga. Brasília, DF; 2001. Disponível em: <http://www.dominiopublico.gov.br/download/texto/me001936.pdf $>$. Acesso em: 1 abr. 2013.

DURAND, G. As estruturas antropológicas do imaginário: introdução à arquetipologia geral. Lisboa: Presença. 1989.

DURAND, Y. L'exploration de l'imaginaire: introduction a la modelisation des universmythiques. Paris: l'Espacebleu, 1988.

GOVERNO DE GOIÁS. Secretaria de Estado de Gestão e Planejamento. Instituto Mauro Borges de Estatísticas e Estudos Socioeconôemicos. Mapas das microrregiões de Goiás - IBGE. Goiania: IMB, 2013. Disponível em: $<$ http://www.seplan.go.gov.br/sepin/viewcad.asp?id_cad=5000\&id_ not $=6>$. Acesso em: 1 abr. 2013.

LEFÈVRE, F.; LEFÈVRE, A. M. C. Pesquisa de representação social: um enfoque qualiquantitativo. Brasília, DF: Líber 2010.

LOUREIRO, A. M. L. A velhice, o tempo e a morte: subsídios para possíveis avanços do estudo. Brasília: Editora Universidade de Brasília, $1^{\text {a }}$ reimpressão, 2000. 
LOUREIRO, A. M. L. O teste AT-9 na busca do imaginário. Brasília, DF: Editora Universidade de Brasília, 2004.

MCLAREN, P. Multiculturalismo revolucionário: pedagogia do dissenso para o novo milênio. Porto Alegre: Artes Médicas Sul, 2000.

MIERMONT, J. et al. Dicionário das terapias familiares: teoria e prática. Porto Alegre: Artmed, 1994.

MOURA, C. Quilombos: resistência ao escravismo. São Paulo: Ática, 1987.

MUNANGA, K. Mestiçagem como símbolo da identidade brasileira. In: NASCIMENTO, A. O quilombismo: documento de uma militância pan-africanista. Petrópolis: Vozes, 1980.

NASCIMENTO, B. O conceito de quilombo e a resistência cultural negra. Afrodiáspora, Rio de Janeiro, n. 6-7, p. 41-9, 1985.

OLIVEIRA, J. A. P. Desafios do planejamento em políticas públicas: diferentes visões e práticas. In: Encontro da ANPAD, 29., 2005, Brasília, DF. Anais... Rio de Janeiro: ANPAD, 2005. p. 273-88.

PEREZ GÓMEZ, A. I. A cultura escolar na sociedade neoliberal. Porto Alegre: Artes Médicas, 2001.

PINSKY, J.; PINSKY, C. B. (Orgs.). História e cidadania. 5. ed. São Paulo: Contexto, 2010.

RATTS. A. J. P. A geografia entre aldeias e quilombos. In. ALMEIDA, M. G.; RATTS, A. J.P. (Orgs.) Geografia: leituras culturais. Goiânia: Alternativa, 2003. p. 29-48.

SARTRE, J. P. Reflexões sobre o racismo. São Paulo: Difusão Européia do Livro, 1960.

TORRES, C. A. Democracia, educação e multiculturalismo: dilemas da cidadania em um mundo globalizado. Petrópolis: Vozes, 2001. 


\section{Informações dos autores}

Fátima Gonçalves Messias Takahashi: Doutoranda em Saúde Pública, Instituto de Educação Superior Latinoamericano - IESLA-MG. Contato: fgmhashi@hotmail.com

Vicente Paulo Alves: Doutor em Ciências da Religião, Universidade Metodista de São Paulo, Brasil. Coordenador e Professor no Programa de Pós-Graduação Stricto Sensu em Gerontologia da Universidade Católica de Brasília, Distrito Federal, Brasília, Brasil. Contato: vicerap@gmail.com 
